\title{
LENGUA VIVA EN LA TRADUCGIÓN. VARIEDADES Y ACENTOS EN UN MODELO INTEGRADO: A PROPÓSITO DE ÁGUILAS Y ÁNGELES, DE JULI ZEH
}

\author{
Jenny BRUMME \\ Universitat Pompeu Fabra, Barcelona
}

\section{RESUMEN}

En este artículo se propone un modelo integrado para el análisis de la oralidad ficticia en textos y sus traducciones, con especial atención a su dimensión diatópica. Como punto de partida, se retoman los principales conceptos del marco teórico desarrollado por el estructuralismo alemán, como, por ejemplo, la cadena de variedades, la direccionalidad de la estratificación variacional y la distinción entre el lenguaje de la inmediatez comunicativa y el lenguaje de la distancia. A pesar de su rigidez y de algunas inconsistencias, el modelo permite clasificar las técnicas de traducción y, de este modo, profundizar en el funcionamiento de los textos traducidos. El enfoque se aplica al habla de los personajes en la novela Águilas y ángeles, de Juli Zeh. Para ello, se seleccionaron dos caracteres cuya habla contiene rasgos diatópicos y se compararon con sus traducciones al castellano, inglés, catalán y francés.

PALABRAS CLAVE: traducción, cadena de variedades, habla del personaje, oralidad ficcional, variedad diatópica.

\section{ABSTRACT}

This article proposes an integrated model for analysing fictional orality in texts and their translations, with special focus on its diatopic dimension. It starts by identifying the main concepts of the theoretical framework developed by German structuralism, such as the chain of varieties, the directionality of variational stratification, and the distinction between the language of communicative immediacy and the language of distance. Despite its rigidity and some inconsistencies, the model makes it possible to classify the translation techniques used and thus gives deeper insights into how translated texts work. The approach is illustrated by analysing how the characters speak in Juli Zeh's novel Eagles and Angels. To this end, two characters whose speech contains diatopic features were selected and compared with their translations into Spanish, English, Catalan and French.

KEYWORDS: translation, chain of varieties, character speech, fictional orality, diatopic variation. 


\title{
1. LENGUA VIVA EN LA FICCIÓN ESCRITA
}

El lugar donde, en un texto de ficción escrito, mejor se pueden recrear ciertos rasgos cercanos de la lengua viva suele ser el discurso del personaje, es decir, en palabras de Bustos Tovar, «un discurso que corresponda a la naturaleza individualizada del sujeto hablante en el texto» (2006: 13). Si el interés de Bustos Tovar por esta relación entre la lengua hablada y la escritura siempre se ha dirigido hacia manifestaciones históricas de la lengua española (cf. 1996, 1998, 2006), yo he atendido más bien a la ficción contemporánea escrita en diversas lenguas (cf. Brumme 2008 y 2012; Brumme y Espunya 2012). El problema de fondo, sin embargo, sigue siendo el mismo, aunque se describa la aparición de la lengua viva en la escritura en términos de mímesis conversacional, de oralidad «fingida» o de oralidad representada ${ }^{1}$. Podríamos añadir más rótulos que se han utilizado. Siempre se trata de indicar el «procedimiento por el cual el diálogo escrito refleja aspectos del diálogo hablado» (Bustos Tovar 2006: 32).

La mayoría de las veces se ha entendido esa aparición del lenguaje hablado en el texto escrito como incorporación de ciertos rasgos diatópicos, diastráticos y diafásicos ${ }^{2}$ a la ficción escrita y, en particular, al habla del personaje con el fin de profundizar en su perfil y otorgar verosimilitud a su comportamiento. Bustos Tovar diferencia, a grandes rasgos, entre dos tendencias de acercarse a lo que él llama «textualizar la oralidad» (2006: 39):

\begin{abstract}
Algunos han interpretado que esto significa la presencia en la escritura de términos que «abundan más en la lengua hablada» o que reflejan el habla de un grupo social profesional; otros, en cambio, se han fijado en el modo en que el diálogo inserta marcas o señales que indican la situación de los interlocutores en el acto real de emisión del mensaje. (Bustos Tovar 2006: 32)
\end{abstract}

Aunque Bustos Tovar admite que las dos líneas son legítimas, se desprende claramente de su planteamiento que aboga por la segunda línea, cuyo interés me gustaría realzar, si bien en mis propios estudios he prestado más atención a los rasgos concretos ${ }^{3}$ que evocan la situación comunicativa. Ello se debe, fundamentalmente, a que mi investigación se ha

${ }^{1}$ Para saber más sobre estos últimos términos, cf. Brumme (2008: 9-11) y Brumme (2012: 13-33).

${ }^{2}$ Sigo el enfoque adoptado por Koch y Oesterreicher (2007: 35-42) para describir el espacio variacional histórico-idiomático entre la inmediatez y la distancia comunicativa. Soy consciente de que ha recibido severas críticas. Sin embargo, para el análisis contrastivo y de traducciones ofrece un marco manejable, si bien rígido en su procedencia estructuralista.

${ }^{3}$ Bustos Tovar menciona los «rasgos léxico-semánticos y sintácticos» (2006: 32), pero se pueden añadir otros más. 
desarrollado atendiendo a la primera línea en el marco de los Estudios de traducción, ubicación que justifica, también, la presente aproximación.

\section{LENGUA VIVA EN LA TRADUCCIÓN}

Como ya he dicho, el lugar idóneo para incorporar ciertos rasgos procedentes de la cadena de variedades (cf. Koch y Oesterreicher 2007: 38) es el habla del personaje y, por antonomasia, el discurso directo. Soy consciente de que esta afirmación simplifica mucho la evocación del lenguaje de la inmediatez comunicativa ${ }^{4}$ en el texto de ficción, pero para los propósitos que tengo sirve plenamente. En los Estudios de traducción, los textos que llevan marcas diatópicas y/o diastráticas han llamado la atención de los estudiosos ${ }^{5}$, puesto que, tal y como ya afirmaba Coseriu, el lenguaje cumple, en estos casos, aparte de la función designativa, al mismo tiempo una función «sintomática», es decir, «la función de describir o caracterizar a los hablantes que lo producen» (Coseriu 1977: 230). Aportando el ejemplo del dialecto bávaro, Coseriu afirma que tales rasgos evocan asociaciones que en la comunidad lingüística de partida suelen relacionarse con aquella variedad (1977: 231). De ahí que concluya que «no es posible una traducción sino únicamente una adaptación» (1977: 231). La solución en la lengua meta (LM) ${ }^{6}$ depende, según Coseriu, «de la configuración "diatópica” (dialectal), "diastrática” (sociocultural) y "diafásica” (estilística) de la lengua de llegada y de las asociaciones que con tal configuración se relacionen en la comunidad que habla esta lengua» (Coseriu 1977: 231).

Me parece que esta observación sigue plenamente vigente, si bien hay que considerar que la configuración de la LM solo es uno de los múltiples condicionantes de una traducción. Gran peso tienen la tradición literaria, los hábitos de lectura, las expectativas de los lectores, la aceptación de las variedades entre los hablantes, etc. En este sentido, se han descrito y sistematizado repetidamente y con mucho detalle las técnicas de traducción (cf. Hurtado y Molina 2000), sobre todo en lo que concierne a los rasgos de la variación diatópica presentes en el texto fuente (TF) y, en este con-

4 Aquí también sigo la propuesta de Koch y Oesterreicher, que prevé incorporar una cuarta dimensión, es decir, la inmediatez comunicativa, en la descripción del espacio variacional de una lengua histórica (2007: 37-40). Para términos concurrentes como variedad diamésica o variedad diamedial cf. Brumme (2012: 18-20).

${ }^{5}$ Cf., por ejemplo, Assis (2012), Briguglia (2013), Czennia (2004), Ellender (2015), Federici (2011), Grutschus (2016), Hatim y Mason (2005: 81-92), Marco (2002: 77-86), Ramos Pinto (2016), Soto Vázquez (2014).

${ }^{6}$ Utilizo las siguientes abreviaturas: LM - lengua meta, TM - texto meta, LF - lengua fuente y TF - texto fuente. 
texto, a los rasgos diastráticos. El panorama que se ha obtenido me ha hecho retomar a mí y a otros estudiosos de la traducción el problema desde una perspectiva más holística, concretamente, desde la distinción entre los rasgos universal-genéricos del lenguaje de la inmediatez comunicativa y los rasgos histórico-idiomáticos o histórico-contingentes ${ }^{7}$. De esta manera, se reconoce mejor la imbricación entre las distintas variedades de una lengua, «que no coexisten de forma completamente inconexa» (Koch y Oesterreicher 2007: 38).

Sobre todo, la direccionalidad que señalan Koch y Oesterreicher me ha parecido trascendente para los Estudios de traducción. Partiendo del esquema propuesto por Marco (2002: 81), he elaborado una representación para visibilizar las técnicas que se pueden observar en las traducciones y situarlas en la cadena de variedades (cf. figura 1).

El esquema original de Marco intenta sistematizar las técnicas que se observan en la traducción de textos fuente con rasgos diatópicos (2002: 80).

Figura 1. Modelo adoptado según Marco (2002: 81)

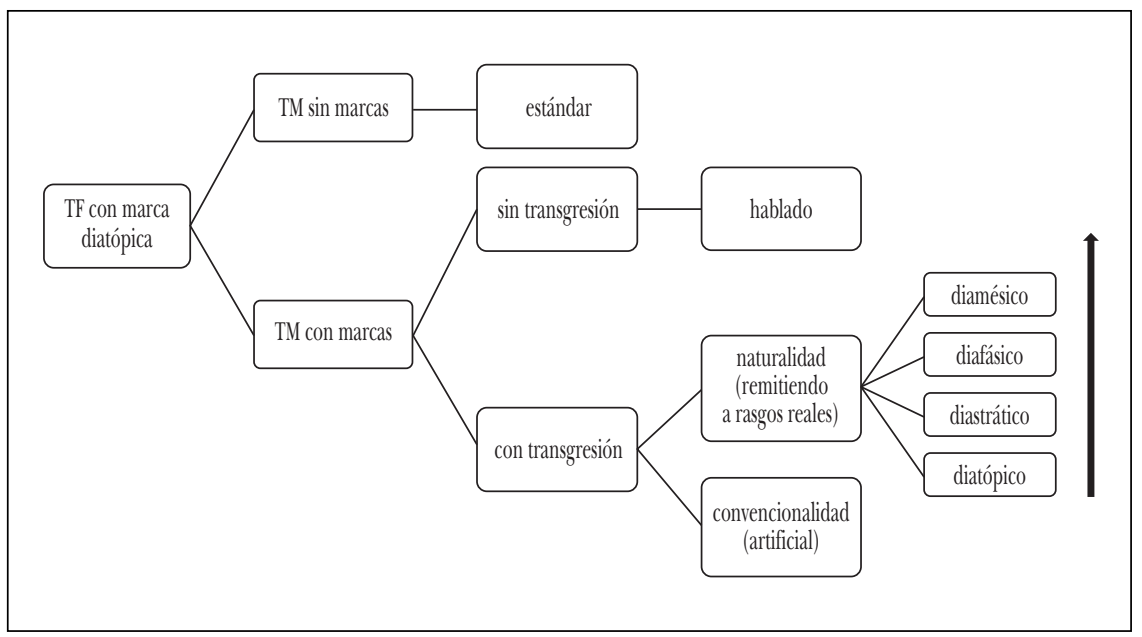

${ }^{7}$ Koch y Oesterreicher (2007: 23-24) introducen esta distinción a partir de la definición del lenguaje humano de Coseriu, quien lo concibe en los niveles universal, histórico e individual. Hay que tener en la mente que una traducción siempre se elabora en el nivel del discurso, es decir, se elabora un texto a partir de otro texto. Asimismo, interviene en la formulación de este 'nuevo' texto el nivel de las lenguas históricas y sus tradiciones discursivas, por lo que la comparación entre el TF y el TM se presenta casi automáticamente en términos de disconformidades y discrepancias, a menudo tachadas de «pérdidas». Pero si se adopta la perspectiva más general que ofrece el nivel universal, es posible apreciar las convergencias que, al fin y al cabo, permiten la traducción, es decir, trasladar lo que dice y señala el TF. 
Una primera opción es distinguir entre la posibilidad básica de producir un texto meta (TM) sin marcas, indicada en la figura 1 con el nivel no marcado del estándar, y la opción de confeccionar un TM con marcas ${ }^{8}$. Si el traductor opta por esta última vía, se da otra coyuntura, es decir, elaborar un texto no necesariamente estándar, pero sin transgresión, o, por el contrario, optar por transgredir la norma lingüística en algún aspecto ${ }^{9}$ (Marco 2002: 80). Dependiendo de las prácticas traductoras vigentes en cada momento, Marco observa, y así lo visualiza en su esquema original, que algunos de los traductores optan por crear una configuración artificial de rasgos de diversa índole que no evoquen en el lector meta la imagen de un dialecto concreto de su cultura. Es lo que señala como convencionalidad opuesta a naturalidad (2002: 81).

En lo que concierne a las opciones de conferir naturalidad a las traducciones, ha sido útil incorporar la cadena de variedades y la direccionalidad (indicada con la flecha en la figura 1) que señalan Koch y Oesterreicher, partiendo de las ideas de Coseriu:

... es importante reconocer que entre las diferentes dimensiones de la variación lingüística se establecen relaciones en una dirección fija determinada, de tal modo que, en la sincronía, lo diatópico puede funcionar como diastrático y lo diastrático como diafásico, pero no a la inversa. Así, una expresión dialectalmente muy marcada de un hablante puede ser calificada como diastráticamente baja. Al mismo tiempo, una expresión que en sí está marcada como diastráticamente baja puede ser empleada por hablantes de procedencia social muy diversa en una situación relajada e informal (diafásicamente baja). (Koch y Oesterreicher 2007: 38)

Si esto lo aplicamos a las técnicas de traducción, podemos ver cómo muchos traductores intentan contrarrestar la falta de rasgos diatópicos en

\footnotetext{
${ }^{8}$ Esta opción correspondería a recrear la riqueza diatópica del TF con elementos del espacio dialectal de la lengua meta. Así pues, se podría recrear el bávaro sustituyéndolo por el andaluz. Sin embargo, y así ya lo observaba Coseriu (1977: 231), el efecto en los lectores sería distinto, puesto que los campos indexicales de estas dos variedades históricas difieren. Aunque exista esta opción y que se haya practicado en la historia de la traducción, se ha ido estableciendo la convención de recurrir a otras posibilidades (cf. tabla 2) para dejar al margen aquellas traducciones que se valen de la variación dialectal en el TM (cf. Czennia 2004).

${ }^{9}$ Marco (2002: 81) indica como ejemplos de esta transgresión la elisión de vocales o consonantes en el nivel ortográfico (tomao en vez de tomado), estructuras incorrectas en el nivel gramatical (delante mío en vez de delante de mí) y palabras no aceptadas en la lengua estándar escrita (e-mail para correo electrónico). Téngase en cuenta que los ejemplos para el español son míos, puesto que Marco trabajó con el inglés y el catalán. Confío en que los lectores de este artículo reconocerán los efectos que tendría tal opción introducida por un traductor y no entro más en detalle.
} 
el TM recurriendo a rasgos diastráticos, diafásicos y, en las lenguas que han desarrollado esta dimensión, diamésicos ${ }^{10}$.

Sin embargo, también se ha podido observar que la función «sintomática» que desempeñan los rasgos diatópicos en el TF se compensa en el TM mediante la referencia a una situación de inmediatez comunicativa. Por supuesto, la evocación de la situación (con los actos de habla, la estructura por turnos de palabra, las referencias quinésicas y proxémicas que contiene) se suelen desarrollar ya en el TF. Pero la traducción puede reforzar o intensificar alguno de los elementos evocados para compensar otros cuya elaboración el traductor ha desestimado. Es la dimensión donde he indicado 'hablado' (en el sentido conceptual) en el esquema, si bien puede ser difícil argumentar la diferencia entre esta dimensión y la 'lengua estándar'. En cualquier caso, hay que recordar que el esquema (figura 1) se basa principalmente en textos de ficción realizados en el medio gráfico que, valiéndose de una serie de rasgos diatópicos, evocan o remiten a situaciones de inmediatez comunicativa.

Estas consideraciones me llevan nuevamente a las afirmaciones de Bustos Tovar. Para «oralizar» el habla del personaje es esencial, en su opinión, la «adecuación del enunciado a la acción» (2006: 34). No es tan importante «cómo hablan los personajes, sino cómo actúan [...]. Decir y hacer constituyen un todo» (2006: 27). En este sentido, se entiende por qué muchas traducciones 'funcionan' sin recurrir a marcas lingüísticas particulares, ni siquiera a las de la dimensión diafásica, es decir, al nivel estilístico. Así pues, me parece importante seguir describiendo aquella dimensión de mi esquema que se sitúa con la etiqueta 'hablado' en un continuo direccional de variación.

\section{VARIEDAdes y aCentos EN ADLER UND ENGEL (2001), DE JUli ZeH}

A continuación, quisiera esbozar cómo se ha traducido el habla de dos de los muchos personajes en la novela Adler und Engel (2001), de Juli Zeh. En lo que concierne al formato literario, la novela no presenta grandes sorpresas. La sinopsis de la editorial Siruela subraya que está «escrita con un lenguaje ágil y actual». Efectivamente, prevalecen los diálogos en la narración del yo narrador. El protagonista, Max (33 años y experto en Derecho internacional), intenta descubrir lo que ocurrió con sus antiguos amigos del instituto, Jessie y Shershah, quienes murieron en circunstancias

${ }^{10}$ Mantenemos esta dimensión para aquellas lenguas que la han desarrollado más como el inglés y el francés. Esta dimensión puede parecer superflua, puesto que existe el nivel de 'hablado'. No obstante, me parece necesario conservarla, vistas las diferencias con las que se evoca la oralidad ficcional entre lenguas como el inglés, por un lado, y lenguas como el castellano, por el otro. 
poco claras. El lector va descubriendo paulatinamente y a través de un entramado de personajes secundarios que todo tiene que ver con la guerra de los Balcanes:

Su extraño amor es un producto de esa cínica unión entre héroes de una guerra civil, genocidas, traficantes de drogas y políticos de la ONU que permiten cosas espantosas para impedir otras que lo son aún más. Esta primera novela de Juli Zeh, traducida a más de quince idiomas, ofrece un panorama aterrador e impresionante del mundo tras la caída de las ideologías, y ha situado a su autora entre las voces más prometedoras de la literatura alemana contemporánea. (Zeh 2002a: Sinopsis)

Juli Zeh trata, por tanto, un tema candente y de gran envergadura. Varias reseñas en los medios alemanes, en cambio, han criticado la escasa calidad literaria de lo que consideran una novela de carretera (road novel), escrita en un lenguaje plagado de expresiones estereotipadas y metáforas corrientes. La expresión de los personajes, sobre todo los cuatro principales (Max, Jessie, Shershah y Clara), se sitúa a menudo entre un nivel diafásico muy bajo y la jerga de los drogadictos. Vista la gran cantidad de personajes, el habla de algunos de ellos se perfila mediante rasgos particulares, llamados, en mi opinión, a ayudar al lector a situarse en una trama extremadamente complicada.

Entre estos últimos, he seleccionado dos personajes cuya expresión en alemán lleva algún rasgo que indica su origen: el artista y Rufus. En el caso del artista, la escritora marca la procedencia a través de rasgos del dialecto de Viena, del lugar, por tanto, donde ocurre gran parte de la acción narrada. En cambio, el habla de Rufus revela, mediante el uso de alguna expresión y también por ciertos comentarios metalingüísticos, que no es hablante nativo del alemán. Rufus, estadounidense de origen, se expresa generalmente en alemán, pero en un alemán impregnado de unos pocos atributos tomados del inglés, que lo individualizan frente al habla del resto de los personajes. Por tanto, la lengua fuente (LF) presenta transferencias de otra lengua que Corrius y Zabalbeascoa (2011) han estudiado como L3.

\section{ADLER UND ENGEL EN ESPAÑOL, CATALÁN, INGLÉS Y FRANCÉS}

Tal y como indica la sinopsis, la novela Adler und Engel ha sido traducida a varias lenguas, entre las que figuran el español (2002a, por Rosa Pilar Blanco $)^{11}$, el catalán (2002b, por Judit Romeu Labayen), el inglés (2003,

11 En el análisis parto de la suposición de que las traducciones reflejan la variedad estándar de los países de publicación (España, Francia y Gran Bretaña), sin, por ello, excluir otras áreas de habla española, francesa e inglesa, respectivamente, donde se podrían vender. En el caso concreto del español, el análisis se realiza, por tanto, teniendo en cuenta el espacio 
Christine Slenczka) y el francés (2004, por Jörn Cambreleng). En lo que sigue, voy a describir los rasgos que sobresalen en el habla de los dos personajes mencionados a partir de fragmentos que considero ilustrativos. Para cada caso, voy a indicar brevemente el proceder en las traducciones, empezando por la española, seguida de las traducciones al catalán y al inglés para incorporar, en ocasiones, las soluciones en la traducción francesa, si las técnicas difieren. De esta forma, quisiera ilustrar cómo se concreta la cadena de variedades en los TM siguiendo la figura 1. La comparación de las soluciones en diversas lenguas también ofrece la posibilidad de destacar las dimensiones que se (re-)elaboran en las traducciones. Para adelantar los resultados, son estas las dimensiones de lo que se señala como 'hablado' y 'diamésico' en el esquema (cf. figura 2).

FIGURA 2. Principales dimensiones para recrear la oralidad ficcional

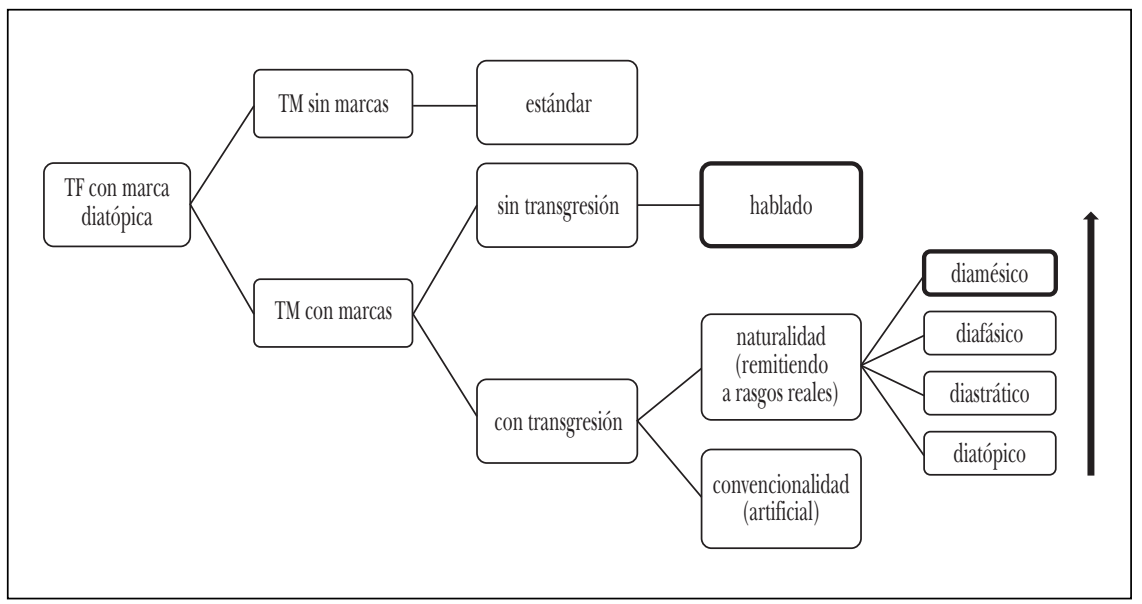

\subsection{El artista y el alemán vienés}

En el siguiente fragmento, el protagonista Max le hace una visita inesperada al artista. En esta visita lo acompaña Clara, una estudiante de psicología, que quiere escribir su trabajo de final de carrera sobre el caso de $\mathrm{Max}^{12}$.

variacional de la lengua española en la península ibérica. De forma similar, se procede para el francés e inglés, que cuentan con traducciones publicadas en París y Londres, hecho que indica que se ha optado por el estándar que corresponde a la variedad europea.

${ }^{12}$ La primera réplica del fragmento extraído se refiere a Clara: «Increíble, exclama el artista admirado, hay que ver cómo la [a Clara] manejas» (Zeh 2002a: 253). 
En los turnos de habla que he seleccionado para el análisis, el artista manifiesta haber convertido a Shershah, es decir, su cadáver, en escultura.

Puesto que a Max le interesa aclarar las muertes violentas de sus antiguos amigos Jessie y Shershah, encamina la conversación en esta dirección. El artista responde con franqueza jactándose incluso de haber 'trabajado' el cadáver de Shershah. Sus turnos de habla llevan ciertos rasgos fonéticos del vienés ( $h o b$ en vez de $h a b$ 'tengo', $i$ en vez de $i c h$ 'yo', etc.), pero sobre todo son las marcas léxicas las que funcionan como shibboleth ${ }^{13}$ remitiendo a palabras también conocidas por los no vieneses. Se trata, por ejemplo, de Herrschaftszeiten 'ay, carajo' ${ }^{14}$, Haberer 'admirador' ${ }^{15}$, fesch 'guapo' ${ }^{16}$, Schneckn 'novia' ${ }^{17}$. Pero, igualmente, el nivel sintáctico ${ }^{18}$ sigue lo típicamente hablado en alemán. En resumen, el TF evoca una situación de inmediatez comunicativa valiéndose tanto de rasgos universal-genéricos (turnos de habla, marcadores de discurso, etc.) como de rasgos histórico-idiomáticos que comprenden los aspectos comentados en el nivel fonético, sintáctico y léxico.

(1-al) Herrschaftszeiten, sagt der Künstler, die host aber im Griff.

Ich setze mich wieder hin.

Und jetzt vergessn wir die Raubersgschichtn, sagt er, du hast den Haberer doch kennt?

Shershah, frage ich.

I hob ihn Adonis ghaaßn, sagt er, der woar so was von fesch. Den hob i gar net dawortn können. Sei Figur is mei Meisterstück.

Ist mir klar, sage ich.

Ja und dem sei Schneckn, fragt er, kennst die aa?

Wen, frage ich.

Na wie haaßts denn schnell, sagt er, die Klaane vom Herbert.

(Zeh 2001: 331-332) $)^{19}$

${ }^{13}$ Me refiero a la definición que ofrece el Merriam Webster, en particular «2 a: a use of language regarded as distinctive of a particular group. accent was ... a shibboleth of social class -Vivian Ducat». En principio, no se trata de otra función que la «sintomática» indicada por Coseriu.

${ }^{14}$ Se trata de una exclamación que indica enojo e indignación y que se considera típica del bávaro y el austriaco coloquial (cf. «Herrschaftszeiten [nochmal] (bayrisch, österreichisch umgangssprachlich: Ausruf des Unwillens, ungeduldiger Entrüstung)», Duden).

${ }_{15}$ El Duden lo califica de «Gebrauch: österreichisch umgangssprachlich» ('Uso: austriaco coloquial').

${ }^{16}$ Se describe en la primera acepción como «(österreichisch und umgangssprachlich) hübsch, flott, sportlich aussehend» ('(austriaco y coloquial) guapo, chic, deportivo’ (Duden).

${ }^{17}$ El Duden indica: «Gebrauch: landschaftlich, besonders süddeutsch, österreichisch» ('Uso: regional, sobre todo del sur de Alemania, austriaco').

${ }^{18}$ No entro en detalles. No abundan los estudios sobre este aspecto. A título de ejemplo, remito a los trabajos de López Serena (2007 y 2012).

${ }^{19}$ Utilizo la cursiva en el TF y los TM para indicar las cuatro palabras que analizo. 
Si pasamos a las traducciones, podemos observar que la referencia a una situación de inmediatez comunicativa se mantiene por la propia acción de los personajes que se describe. Por tanto, son parámetros que no cambian, pero que se podrían perfilar recurriendo a elementos típicos de una situación similar en el TM. Siguiendo la práctica traductora actual, estos elementos no comprenderán rasgos diatópicos de la LM, puesto que ya no se da o solo se da en circunstancias excepcionales la combinatoria de traducir el TF con marcas diatópicas por un TM con marcas diatópicas (Rabadán 1991: 17; Marco 2002: 77-86; Hurtado Albir 2000: 583-590). Por consiguiente, es de esperar que los traductores se valgan de otros recursos para singularizar el habla del personaje. En primer lugar, serán los rasgos universal-genéricos los que se podrán reelaborar, y, en segundo lugar, los rasgos histórico-idiomáticos que el traductor considere convenientes. Si seguimos la cadena de variedades (cf. figura 3), se podrían aprovechar las dimensiones inmediatamente superiores a la dimensión diatópica, es decir, la diastrática y la diafásica, y, si eso es posible en la LM, la aquí llamada dimensión diamésica.

FIGURA 3. Coyuntura improbable de traducción: marca diatópica por marca diatópica

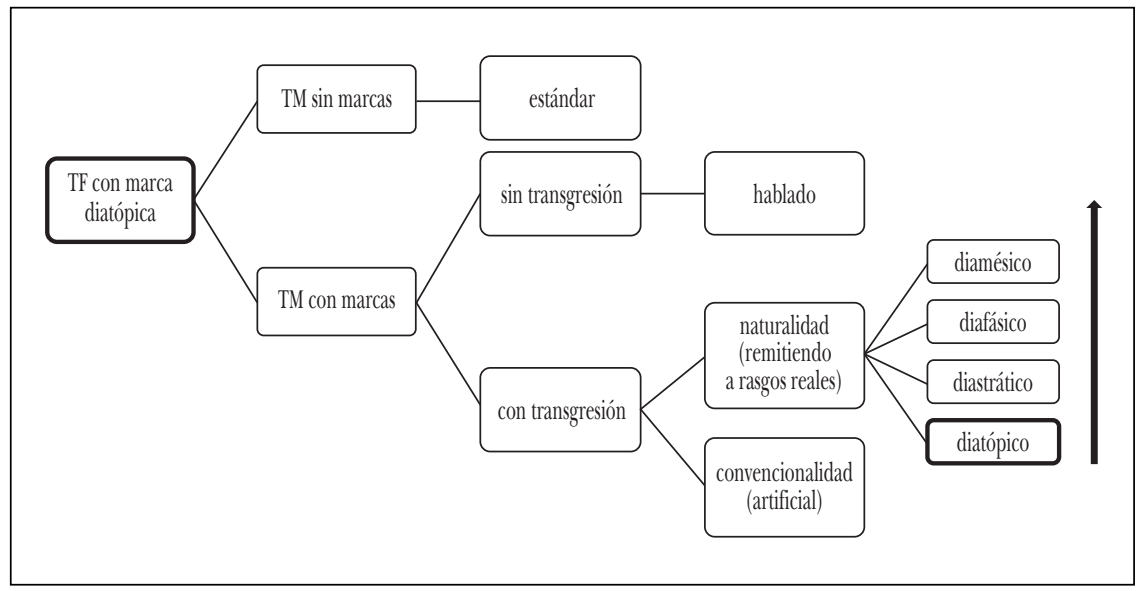

Las tres traducciones efectivamente elaboran, en primer lugar, el habla que correspondería a una situación de inmediatez comunicativa. No se alteran los turnos de los personajes y se respetan los párrafos, así como gran parte de la puntuación no normativa (por ejemplo, la ausencia de las comillas en alemán para señalar el diálogo). La traducción al español recupera también, en cierta medida, el efecto shibboleth de alguna de las cuatro palabras indicadas: 
(1-es) Increíble, exclama el artista admirado, hay que ver cómo la manejas.

Vuelvo a sentarme.

Y ahora, olvidemos las historias de ladrones, dice él, tú conociste al novio, ¿no?

¿A Shershah?, pregunto.

Yo le llamaba Adonis, dice, era un guaperas. Me moría de impaciencia por recibirle. Su figura es mi obra maestra.

No lo dudo, le aseguro.

Oye, ¿conoces también a su piba?

A quién, pregunto.

Bueno, cómo se llama, la pequeña de Herbert, añade.

(Zeh 2002a: 253)

Las dos primeras, Herrschaftszeiten y Haberer, muy marcadas dialectalmente, no llevan ninguna marca en el TM: se han traducido por ¡increíble! y novio. Destaca piba 'niña, joven' que, según el DrAe, en España se considera «jergal», además de poseer connotaciones diatópicas (Argentina y Bolivia, pero también Canarias). Asimismo, la palabra guaperas lleva las marcas de «despectiva» y «coloquial». Por tanto, la evocación concreta del origen austriaco-vienés del personaje no se transmite, pero, en general, se reelabora la situación de inmediatez comunicativa, evocada, en gran parte, gracias al vertiginoso cambio de turnos entre los dos personajes y los rasgos universal-genéricos (cf. Koch y Oesterreicher 2007: 72-104), como los marcadores discursivos (oye, bueno) y las modalizaciones (me moría). Se añade la intención de reforzar la concepción hablada a través de léxico coloquial y hasta jergal.

Técnicas parecidas de traducción se observan en las versiones catalana, francesa e inglesa, aunque estas últimas, por la configuración concreta de la lengua histórica y los hábitos de escritura literaria, son capaces de indicar también la dimensión diamésica. En la catalana, se percibe claramente la voluntad de acercarse al nivel hablado, hecho que 'obliga' a incorporar algún que otro castellanismo como guapo o nòvia ${ }^{20}$, este último no recogido en el Diec2, pero de uso general. La exclamación Déu n’hi do es ponderativa, enfática, y sirve para indicar la importancia de algo o la admiración que produce (GDLC). El uso de esta interjección, muy frecuente en el catalán hablado, como también de home 'hombre', en la última línea del fragmento, así como otros recursos de la lengua hablada como la vaguedad semántica ( una cosa així 'algo así') confieren a la traducción un tono muy natural ${ }^{21}$. A diferencia de la traducción al castellano, se observa una menor presencia de la dimensión diastrática.

\footnotetext{
${ }^{20}$ Cf. «nòvio nòvia $m$ i $f$ » (2015).

${ }^{21}$ En cierta medida, compensa las imprecisiones en la traducción que no quiero comentar en este lugar.
} 
(1-ca) Déu n'hi do, diu l'artista, la tens sota control.

Jo m'assec una altra vegada.

I ara deixem-nos d'històries, diu ell, ¿̇tu coneixies el noi?

El Shershah, pregunto jo.

Jo li deia Adonis, diu ell, era guapíssim. No m'havia imaginat mai que m'arribaria una cosa així. La seva figura és la meva obra mestra.

Ja m'ho imagino, dic jo.

I la seva nòvia, pregunta ell, ¿la coneixes?

¿Qui?

Sí, home, com es deia, diu ell, la filla del Herbert.

(Zeh 2002b: 284)

La traducción al inglés consigue conferir naturalidad al diálogo al explorar el nivel fonético-morfológico con las contracciones usuales en el lenguaje hablado y posibles en la lengua escrita para evocar la hablada (por ejemplo, you've got en vez de you have got 'tienes', he's en vez de he is 'él es') ${ }^{22}$. Asimismo, aparecen interjecciones y marcadores discursivos muy frecuentes en el lenguaje hablado (wow, now, so). Sin embargo, el efecto shibboleth del léxico apenas está presente (por ejemplo, girl para 'novia'). Además, la traducción opta por ser más concreta hablando de body-snatching 'robo de cadáveres' en vez de 'historias de ladrones' y de Herbert's daughter ('la hija de Herbert') en vez de 'la pequeña de Herbert':

(1-in) Wow, the artist says. You've got her under control.

I sit back down again.

Now let's forget about the body-snatching, he says. So you knew our mate here then?

Shershah? I ask.

I called him Adonis, he says. He was amazing. I couldn't wait to get my hands on him. He's my masterpiece.

I know, I say.

And his girl, he says. You know her too?

Who? I ask.

Now, what was her name? he says. Herbert's daughter.

(Zeh 2003: 245-246)

Por tanto, no hay ninguna marca diatópica, pero un incremento de recursos que indican la dimensión diamésica y hablada.

\subsection{Rufus y su acento americano}

El caso de Rufus, abogado y exjefe de Max, es diferente, aunque su habla también lleva alguna marca de su procedencia. Para ello, la escritora

${ }^{22}$ De forma similar, se marcan estos aspectos en la traducción al francés (por ejemplo, «c'était pas croyable ce qu'il était canon») (Zeh 2004: 310). 
se sirve del eye dialect ('dialecto visual') ${ }^{23}$, es decir, selecciona un rasgo de pronunciación típico del inglés, lengua materna del personaje, y lo transmite a través de la grafía alterada. En alemán, la vocal [æ] se suele escribir $\ddot{a}$, por lo que la grafía Mäx indica la pronunciación [mæks]. Esta particularidad comporta algunos comentarios metalingüísticos por parte del protagonista:

(2-al) Mäx, sagt Rufus.

Er ist Amerikaner, und ich habe es nie gewagt, ihn davon abzubringen, meinen Vornamen wie «Mäx» auszusprechen. Als ich die ersten Erfolge feierte in seiner Kanzlei, begann er, mich manchmal «Mäx the mäximal» zu nennen. [...]

Rufus, sage ich.

Wie geht es Ihnen, fragt er.

Sein Wienerisch mit amerikanischem Akzent klingt niedlich wie immer. Wer ihn nicht kennt, unterschätzt ihn gern.

Fein, sage ich. [...]

(Zeh 2001: 27)

La traducción al español 'ajusta' el eye dialect a los hábitos de escritura, por lo que $M \ddot{a} x$ se convierte en Mex con la intención de evocar la pronunciación [mæks]. Consiguientemente, Mäx the mäximal se sustituye por Mex the meximal ${ }^{24}$ :

(2-es) Mex, dice Rufus.

Es americano y nunca me he atrevido a hacerlo desistir de llamarme Mex. Cuando celebré los primeros éxitos en su bufete, él empezó a llamarme a veces Mex the meximal. [...]

Rufus, digo.

¿Qué tal?, me pregunta.

Su vienés con acento americano suena tan encantador como de costumbre. Quien no lo conoce suele infravalorarlo.

Bien, contesto.

(Zeh 2002a: 28-29)

Asimismo, los párrafos seleccionados muestran no solo el uso del eye dialect, sino también la actitud del protagonista ante el habla de Rufus. En

${ }^{23}$ El Oxford Living Dictionary (English) define eye dialect como «(The use of) nonstandard respelling (sometimes for comic effect) to represent dialectal or colloquial pronunciation (as Aw knaow for standard I know), or standard pronunciation not predictable from regular orthography (as enuff for standard enough)».

${ }^{24}$ La traducción al catalán no se vale de una técnica diferente. Convierte Mäx en Meax y Mäx the mäximal en Meax the meaximal. Igualmente, mantiene los comentarios metalingüísticos hablando de «barreja de dialecte vienès amb accent americà» ('mezcla de dialecto vienés con acento americano'; Zeh 2002b: 25-26). 
primer lugar, el comentario de Max indica claramente su malestar ante lo que él considera un error de pronunciación. En segundo lugar, describe una relación asimétrica jefe-empleado que excluye cualquier crítica (corrección de la pronunciación errónea). En tercer lugar, el protagonista Max advierte de la aparente inocuidad de Rufus, idea que se podría sacar del vienés hablado con acento norteamericano. A diferencia del artista (cf. 4.1 ), no se transmite la presencia de la variación diatópica utilizando rasgos dialectales en el texto escrito; simplemente, se indica por el comentario de Max que Rufus, probablemente igual que otros muchos personajes, utiliza el dialecto vienés, puesto que gran parte de la trama ocurre en Viena.

En la traducción al inglés, se da el caso de que la lengua comentada, el inglés, coincide con la LM. En lo que concierne al eye dialect, la traductora ha optado por un alargamiento de la vocal adaptando también el comentario por un impreciso "pronouncing my name the way he does" ("pronunciando mi nombre a su manera'). Sin embargo, esta solución no es del todo coherente al prescindir de modificar el sobrenombre de «Max the Maximal», que ya no refleja ninguna particularidad de pronunciación:

(2-in) Maaax, says Rufus.

He's American, and I've never dared to stop him from pronouncing my name the way he does. After I celebrated winning my first cases, he sometimes called me Max the Maximal. [...]

Rufus, I say.

How are you? he asks.

His American-accented Viennese sounds as cute as ever. Those who don't know him underestimate him.

(Zeh 2003: 14)

$\mathrm{Al}$ igual que en las traducciones al castellano y al catalán, se observa que la traductora ha mantenido la referencia al alemán vienés y su atracción sobre el hablante nativo si es hablado con acento norteamericano ${ }^{25}$.

\section{ReFLEXiOnES FinAleS}

Según Bustos Tovar, el personaje literario «debe comportarse discursivamente de acuerdo con la condición literaria que el autor le ha otorgado» (2006: 33). En el universo ficcional que Juli Zeh crea a través de Max, el yo narrador de Águilas y ángeles, los personajes del artista y Rufus se presentan

${ }^{25}$ Hay que preguntarse naturalmente si el lector de la lengua meta puede apreciar esta percepción positiva del acento norteamericano. Es posible que su valoración del acento extranjero, por ejemplo, en castellano, sea más bien negativo. 
como sujetos hablantes con discursos individualizados (Bustos Tovar 2006: 13). Sin embargo, como bien observa Bustos Tovar:

No es imprescindible que el personaje literario adopte todos los rasgos propios de la «conversación coloquial prototípica», sino sólo aquellos que sirven de marcas de inscripción de lo conversacional en el propio discurso del personaje, combinados con referencias a la situación comunicativa real en la que éstos actúan. (Bustos Tovar 2006: 39)

Tras analizar los ejemplos de traducción y considerar muchos de los estudios realizados, me parece importante subrayar que las traducciones 'funcionan' si vuelven a elaborar, escrupulosamente y con atención a los detalles, la situación de la inmediatez comunicativa. No es tanto la presencia o ausencia de marcas de la cadena de variedades lo que determina una percepción apropiada entre la situación y el comportamiento de los personajes, sino que el lector perciba el comportamiento y la expresión del personaje como verosímil dentro de la situación evocada. Aplico así la idea de Bustos Tovar de que es importante que se (re-)elaboren las «señales que indican la situación de los interlocutores» (2006: 32) y, si en la traducción se pueden recuperar señales a través de la dimensión diastrática y diafásica de la LM, no está de más. Algo similar ocurre con los acentos y la presencia de lenguas extranjeras, a mi parecer. Sin embargo, es probablemente más transcendental que se señalen las dimensiones diamésica y la concepción hablada para que vuelva a surgir una percepción de autenticidad en el TM. 


\section{BIBLIOGRAFÍA}

ALSINA KeITH, Victòria (2012): «Issues in translation of social variation in narrative dialogue». En Jenny Brumme y Anna Espunya (eds.), The Translation of Fictive Dialogue, Ámsterdam/Nueva York: Rodopi, 137-152.

BRIGUGLIA, Caterina (2013): Dialecte i traducció literària. El cas català, Vic: Eumo.

BRUMme, Jenny (2012): Traducir la voz ficticia, Berlín/Boston: de Gruyter.

- (ed.) (2008): La oralidad fingida: descripción y traducción. Teatro, cómic y medios audiovisuales, Madrid: Iberoamericana/Fráncfort del Meno: Vervuert.

- y Anna Espunya (eds.), The Translation of Fictive Dialogue, Ámsterdam/Nueva York: Rodopi.

Bustos Tovar, José Jesús de (1996): «La imbricación de la oralidad en la escritura como técnica del discurso narrativo». En Thomas Kotschi, Wulf Oesterreicher y Klaus Zimmermann (eds.), El español hablado y la cultura oral en España e Hispanoamérica, Madrid: Iberoamericana/Fráncfort del Meno: Vervuert, 359-374.

Bustos Tovar, José Jesús de (1998): «Lengua viva y lenguaje teatral en el siglo XVI: de los pasos de Lope de Rueda a los entremeses de Cervantes». En Wulf Oesterreicher, Eva Stoll y Andreas Wesch (eds.), Competencia escrita, tradiciones discursivas y variedades lingüisticas. Aspectos del español europeo y americano en los siglos XVI y XVII, Coloquio internacional, Friburgo en Brisgovia, 26-28 de septiembre de 1996, Tubinga: Gunter Narr, 421-444.

- (2006): «Lengua común y lengua del personaje en la transición del siglo XV y al XVI». En Consolación Baranda Leturio y Ana Vian Herrero (eds.) (2006), El personaje literario y su lengua en el siglo XVI, Madrid: Instituto Universitario Menéndez Pidal/Editorial Complutense, 13-39.

Corrius, Montse y Patrick ZabalbeascoA (2011): «Language variation in source texts and their translations». Target: International Journal of Translation Studies, 23/1, 113-130.

Coseriu, Eugenio (1977): «Lo erróneo y lo acertado en la teoría de la traducción». En Eugenio Coseriu, El hombre y su lenguaje. Estudios de teoría y metodología lingüistica, Madrid: Gredos, 215-239.

CzENNIA, Bärbel (2004): «Dialektale und soziolektale Elemente als Übersetzungsproblem (Dialect and sociolect as a translation problem)». En Harald Kittel $e t$ al. (eds.): Übersetzung - Translation - Traduction. Ein internationales Handbuch zur Übersetzungsforschung / An International Encyclopedia of Translation Studies / Encyclopédie internationale de la recherche sur la traduction, Berlín: de Gruyter, 505-512.

DrAE = Real Academia Española (2019): Diccionario de la lengua española . Edición del Tricentenario. Actualización 2018. <https://dle.rae.es/>.

Duden. Mannheim: Bibliographisches Institut GmbH (2018). <https://www.du den.de/>. 
ELLENDER, Claire (2015): Dealing with difference in audiovisual translation. Subtitling linguistic variation in films, Oxford: Peter Lang.

Federici, Federico (ed.) (2011): Translating dialects and languages of minorities. Challenges and solutions, Oxford: Peter Lang.

GDLC = Gran Diccionari de la llengua catalana . Barcelona: Enciclopèdia Catalana. $<$ https://www.enciclopedia.cat $>$.

GRUTSCHUS, Anke (2016): «La variation linguistique comme problème de traduction». En Jörn Albrecht y René Métrich (eds.), Manuel de traductologie, Berlín/Boston: de Gruyter, 573-588.

Hatim, Basil e Ian Mason (2005): The Translator as Communicator, Londres/Nueva York: Routledge [1997].

Hurtado Albir, Amparo (2001): Traducción y Traductología. Introducción a la Traductología, Madrid: Cátedra.

- y Lucía Molina (2000). «Translation techniques revisited: A dynamic and functional approach», META, Journal de Traducteurs, 47/4, 498-512.

Koch, Peter y Wulf Oesterreicher (2007): Lengua hablada en la Romania: español, francés, italiano, Versión española de Araceli López Serena, Madrid: Gredos.

López SERENA, Araceli (2007): Oralidad y escrituralidad en la recreación literaria del español coloquial, Madrid: Gredos.

- (2012): «Recreating spoken syntax in fictive orality: an analytical framework». En Jenny Brumme y Anna Espunya (eds.), The Translation of Fictive Dialogue, Ámsterdam/Nueva York: Rodopi, 167-183.

MArco, Josep (2002): El fil d'Ariadna. Anàlisi estilística i traducció literària, Vic: Eumo.

MERRIAM-WEBSTER (2019): Springfield: Merriam-Webster. <https://www.merriamwebster.com/dictionary/shibboleth $>$.

«nòvio nòvia $m$ i $f$ », (2015): Neolosfera. <https://neolosfera.wordpress.com/2014/ 06/05/novio-novia/>.

Oxford Living Dictionary (English) (2019). Oxford: Oxford University Press. $<$ https://en.oxforddictionaries.com/>.

RABADÁn, Rosa (1991): Equivalencia y traducción. Problemática de la equivalencia translémica inglés-español, León: Universidad de León, Secretariado de Publicaciones.

Ramos Pinto, Sara (2016): «Ya care how me speaks, do ya? The translation of linguistic varieties and their reception», inTRAlinea [Special Issue: The Translation of Dialects in Multimedia III]. <http://www.intralinea.org/specials/arti cle/ya_care_how_me_speaks44_do_ya .

RosA, Alexandra Assis (2012): «Translating Place: Language Variation in Translation», Word and Text. A Journal of Literary Studies and Linguistics, Series II, 2, 75-97. [Rui Carvalho Homem y Teresa Caneda (eds.), The Place of Translation, special issue.]

Sinopsis. <http://www.siruela.com/catalogo.php?opcion=autor\&letra=Z\&id_libro $=553>$.

Soto VÁzquez, Adolfo Luis (2014): Dialectos e idiolectos ingleses. Presente y futuro de su traducción al español, Berlín: Logos. 
ZEH, Juli (2001): Adler und Engel. Roman, Fráncfort del Meno: Schöffling \& Co.

- (2002a): Águilas y ángeles, Traducción de Rosa Pilar Blanco, Madrid: Ediciones Siruela.

- (2002b): Àguiles i àngels, Traducció de Judit Romeu Labayen, Barcelona: Editorial Empúries.

- (2003): Eagles and Angels, Translation Christine Slenczka, Londres: Granta Books.

- (2004): L'aigle et l'ange, Traduit de l'allemand par Jörn Cambreleng, París: Belfond. 